\title{
Approaches for evaluation of relief morphometric characteristics influence on spatial distribution of moisture in the soils of steppe part of Crimea
}

\author{
Ielizaveta Dunaieva ${ }^{1}$, Vladimir Pashtetsk ${ }^{1}$, Valentyn Vecherkov $^{1}$, Valentina Popovych $^{1}$, \\ Aleksandr Melnichuk ${ }^{2}$, Vitaly Terleev ${ }^{3}$, Aleksandr Nikonorov $^{3, *}$, Luka Akimov ${ }^{3}$, and \\ Alexander Topaj ${ }^{4}$ \\ ${ }^{1}$ Research Institute of Agriculture of Crimea, Kievskaya, 150, 295453, Simferopol, Crimea, Russia \\ 2 V.I.Vernadsky Crimean Federal University, Vernadskogo pr., 4, 295007, Simferopol, Crimea, \\ Russia \\ ${ }^{3}$ Peter the Great St.Petersburg Polytechnic University, Polytechnicheskaya Str. 29, 195251, \\ St.Petersburg, Russia \\ ${ }^{4}$ LLC «Bureau Hyperborea», Podvoisky ul., 40-2, 193312, St.Petersburg, Russia
}

\begin{abstract}
Data on soil moisture reserves are the basis for decision-making in the agricultural boghara system, because it determines the development of agricultural crops potential, terms of top-dressing and additional fertilizing, and makes it possible to predict yield of agricultural crops. In this article the influence of relief morphometric characteristics on the distribution of precipitation over the territory was studied. The research area is the land of the eastern part of Klepininsky rural settlement of Krasnogvardeysky district, the central part of Crimean Peninsula. The article considers approaches, divided into 2 main categories (according to the type of data used), based on the use of GIS capabilities and remote sensing data, to analyze the soil water content (SWC) using the example of research area and relationship of this parameter to the terrain relief. It was established that the morphometric characteristics of relief affect the amount of soil moisture.
\end{abstract}

\section{Introduction}

Data on soil moisture reserves is the basis for decision-making in the agricultural dry (boghara) system, as it determines the development of crops potential, terms of top-dressing and additional fertilizing, and makes it possible to predict crops yield. Quite a lot of scientific papers have been devoted to the study of soil moisture reserves amount, especially in connection with the influence of hydrological conditions of land use territory, preceding crops, crop cultivation technologies on the structure and hydrophysical properties of the soil [1-5]. To assess the effect of micro-relief scientists use both topographic surveys [6-8] and DEM (Digital Elevation Model) together with the calculated soil moisture

\footnotetext{
*Corresponding author: coolhabit@yandex.ru
} 
indexes [9] and the balance method using hydrological models [10, 11] in their research. Data on the amount of soil moisture reserves are the key information for efficient agricultural production in dry conditions of the Crimean Peninsula. The study of moisture distribution in the soil is especially important in conditions of dry (rainfed) agriculture with the different technologies of tillage, when the use of one technology or another allows more efficient use of soil moisture reserves.

This paper presents research data on the influence of relief morphometric characteristics on the distribution of precipitation over territory and its infiltration into the surface soil horizons.

\section{Materials and methods}

The research area is the lands of eastern part of Klepininsky rural settlement of Krasnogvardeysky district, the central part of the Crimean Peninsula from N45'32'29',

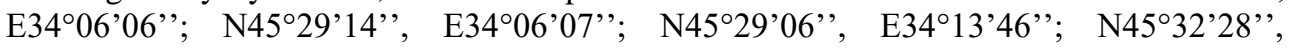
E34 $\left.13^{\prime} 52^{\prime \prime}\right)$. Height above sea level varies from 30 to $50 \mathrm{~m}$ and slopes fluctuate between $0-2^{\circ}$. The research area is 4.684 ha. Shallow ravines with wide flat bottoms and gentle slopes are weakly expressed in the relief. The nameless «tributary» of the Chatyrlyk ravine crosses the research area from the south-east to the north-west. From the north-east the Itaka ravine «falls» into the Chatyrlyk gully, which divides the Klepinino village into two unequal parts: the northern - small and the southern - larger in area.

Soil cover of the territory is mainly represented by the southern low-humus chernozems, the area of which is 3196.26 hectares (68.37\% of the whole territory), other types of soils occupy much smaller areas (see Fig.1).

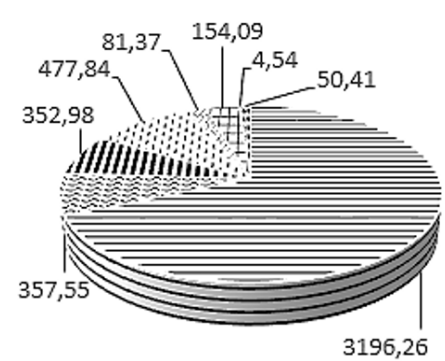

3196,26
吾 $69 \mathrm{~L}$ - southern chernozems, slightly humus

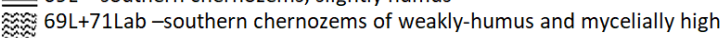

carbonate on loess-type rocks weakly and moderately washed

||||||| 71Lab - southern chernozems of weakly-humus mycelially high carbonate on loess-type rocks weakly and moderately washed

il - southern chernozems of weakly-humus mycelially high carbonate on loess-type rocks

K3 79 abek - chernozems, carbonate rubbled and gravel on eluvium of dense and gravel carbonate rocks, slightly and medium washed

\# 79ek - chernozems, carbonate rubbled and gravel on eluvium of dense and gravel carbonate rocks

\% 195 - ash soils

88L - southern chernozems of weakly- and medium solonetzic on loesslike rocks

Fig. 1. Soil cover of study area, created on the basis of [12].

This article discusses approaches, based on the use of GIS capabilities and remote sensing data, to analyze the moisture content in soils, using the example of research area and attitude of this parameter to the terrain relief. Approaches conditionally can be divided into 2 main categories, according to the type of data used:

\subsection{Analysis, based on the use of DEM data (direct approaches)}

An approach, based on the analysis of the digital elevation model (DEM) using morphometric analysis, calculating terrain slopes and watercourses, determining areas of runoff accumulation. This approach involves the allocation of slope areas (slope), watershed delineation with flow direction, creation of 3D combined map with a slope, contours and soil types and analyzing the spatial distribution of precipitation in the territory.

An approach, based on the use of agro-hydrological modeling using Soil and Water 
Assessment Tool (SWAT) model. [13-16] have used SWAT as a suitable model for stimulating SWC (soil water content) at sub-basin level. These authors have successfully implemented SWAT to simulate SWC in different basins and regions and found that SWAT can generate long-term SWC series. They also compared simulated data with observed data as well as data from other sources, such as SPI and NDVI.

Soil and Water Assessment Tool uses three types of moisture conditions curve numbers. SWAT does not adjust curve numbers for a slope. Therefore, in order to adjust the curve numbers for slope effect, adjustment has to done prior simulation in management input file [17].

In addition, Soil and Water Assessment Tool was used to validate Advanced Microwave Scanning Radiometer (AMSR2) soil moisture in the parts of Puerto Rico.

\subsection{Analysis, based on the use of Earth Remote Sensing data (indirect approaches)}

An approach, based on the use of values of main elements of the water balance according to remote sensing data. This approach is implemented according to the principle of distribution of main elements of the water balance in space (precipitation, evapotranspiration, surface runoff, soil moisture reserves) taking into account the terrain relief (SRTM, Spatial resolution $30 \mathrm{~m}$ ).

Remote sensing data, downloaded through GIOVANNI: soil water content data (Root zone soil wetness monthly 0.5 x 0.625 degree; MERRA-2 Model M2TMNXLND v5.12.4) [18]; precipitation data (GPM GPM_3IMERGM v05; monthly 0.1 degree) [19]; ET data (https://earlywarning.usgs.gov/fews/datadownloads or GIOVANNI-FLDAS Model FLDAS_NOAH01_C_GL_M v001; 0.1 degree) [20]; runoff data (FLDAS Model FLDAS_NOAH01_C_GL_M v001; 0.1 degree) [21].

At the first stage, the distribution of precipitation over the terrain is considered. At the second stage, based on the water balance equation, soil moisture reserves are calculated, then the obtained value is compared with the Earth remote sensing data for SW and field observations.

$$
P-R u n o f f-E T a=S W
$$

where: P - precipitation, mm; Runoff- surface runoff from the territory, mm; ETaevapotranspiration data, $\mathrm{mm}$; SW- soil water content, $\mathrm{mm}$.

Further, the spatial distribution of humidity according to remote sensing data is superimposed on the DEM.

An approach, based on the analysis of plant biomass state, using NDVI index. This approach is based on the hypothesis that variation of values of NDVI in the field may be due to the unequal soil water reserves, which are not evenly distributed over the relief due to the terrain slopes $[22,23]$. The NDVI index is calculated using Landsat 8 Oli/Tirs or Sentinel-2 data, and the spatial variation of the parameter within the field or field plot, occupied by a single crop, is determined. Next, the terrain slope map is compared with the spatial variation of the NDVI values.

\section{Results and discussions}

The results of spatial distribution of soil properties research are presented in the form of maps, the nature of distribution of soil moisture in territory has been studied, and the areas with the highest or lowest concentration of values have been determined. 


\subsection{The results of studies of relief effect on soil moisture, based on the analysis of DEM data}

For a comparative assessment of the spatial variability of moisture reserves on different geomorphological elements and to establish the influence of relief, the capabilities of QGIS 2.18 program were used in this work. Using a digital elevation model it is possible to calculate the morphometric characteristics of the terrain - slopes, exposure, humidity index and much more. As far as the terrain attributes are derived from DEM (SRTM, spatial resolution $30 \mathrm{~m}$ ), the quality and representativeness of this affect the characteristics mentioned above (Fig. 2).

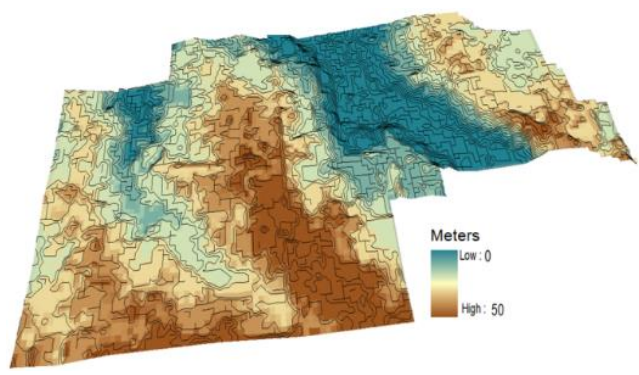

(a)

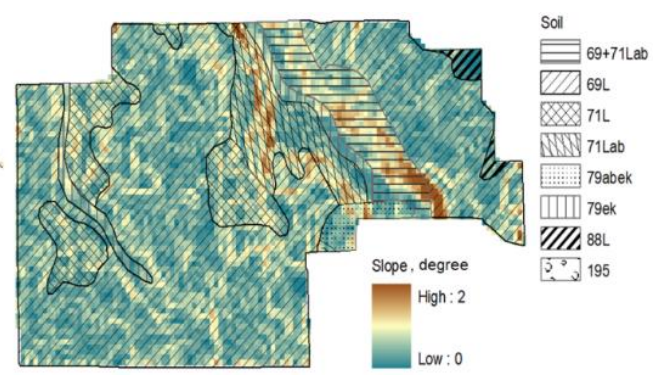

(b)

Fig. 2. The object of research (built on SRTM 30 m): (a) - 3D model of the territory with iso-gypsum; (b) - slope soil cover.

Protrusions and sub-basins were calculated using the SAGA Terrain Analysis module. The first step is to identify potential streams. For doing this, SRTM image with spatial resolution of $30 \mathrm{~m}$ is loaded into the Fillsinks plug-in, where relief recesses are «Filled» with water, resulting in an image in black and white gradient with indication of the recesses. Further processing is carrying out using Channels network and drainage basins plug-in reaches and drainage basins of the territory are delineated (Fig. 3). Similarly, a hydrographic network with the sub-basins can be calculated using the SWAT model (ArcSWAT2009) [24, 25].

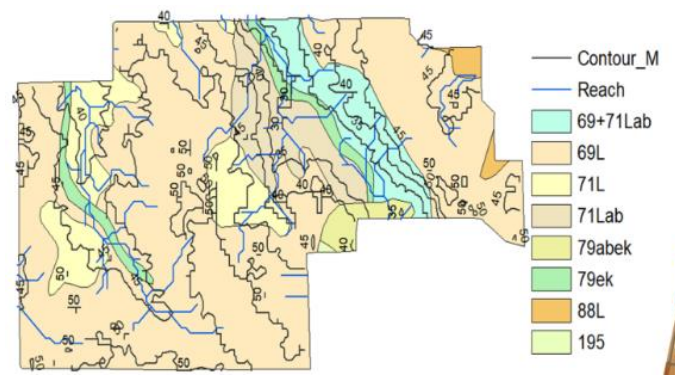

(a)

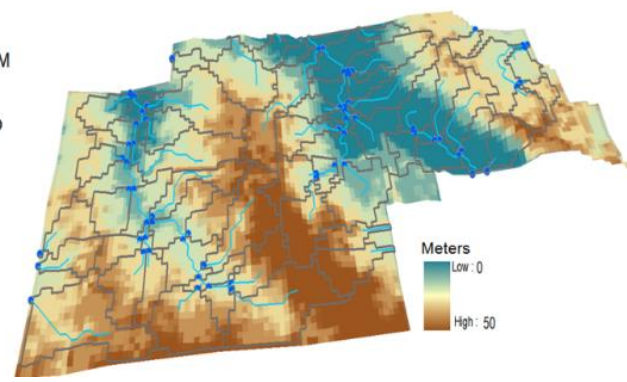

(b)

Fig. 3. (a) - Relief, section horizontal lines through $5 \mathrm{~m}$ with soil cover; (b) - reaches and sub-basins of the study area.

The results of modeling of relief effect on the distribution of moisture in the soil showed that height differences affect the amount of soil moisture across the profile (horizons 0-100 $\mathrm{cm}$ ) for the study area. The first and second options showed a weak correlation between modeling data and field data $-\mathrm{r} 2=0.4$ and between slope and soil moisture content $-\mathrm{r} 2=$ 0.16 . Third option showed that dependence of calculated soil moisture content according to agro-hydrological modeling and field data is moderate, the coefficient of determination $\mathrm{r} 2=$ 
0.63 . Relationship between calculated humidity and slopes is strong, $\mathrm{r} 2=0.80$. To study the distribution of humidity parameter inside the field and analyze the effect of morphometric characteristics on soil moisture reserves it is necessary to use highest resolution DEM (spatial resolution> $10 \mathrm{~m}$ ) and divide the field into elementary areas. Comparison is advisable to carry out for crops with the same time of sowing and preceding crops.

\subsection{Results of research using the water balance method}

Calculation of soil moisture reserves was carried out using QGIS 2.18 software and a raster calculator. The water balance equation typed in the raster calculator and then soil moisture is calculated (see Fig. 4).

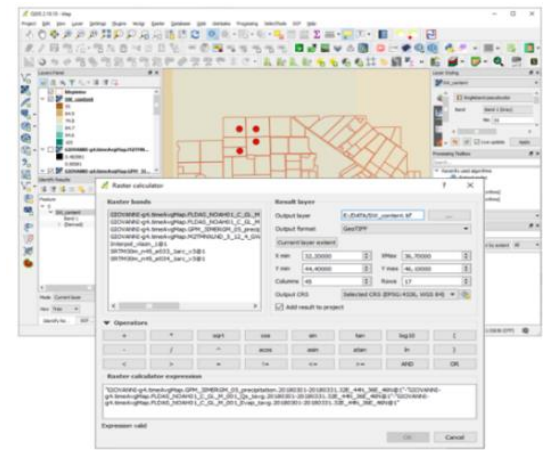

(a)

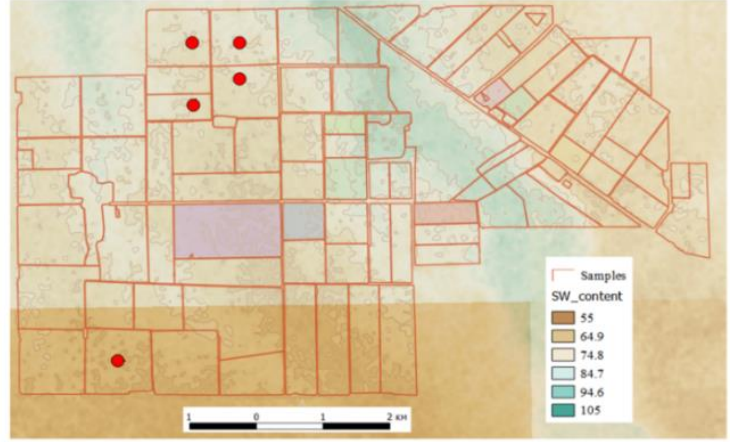

(b)

Fig. 4. (a) - Raster calculator view (equation); (b) - SW content calculated with field data points.

The results of calculating of terrain slopes effect on moisture distribution in the soil showed that height differences affect the amount of soil moisture. Relation between the calculated soil moisture content (remote sensing data) and field data is moderate, the coefficient of determination $\mathrm{r} 2=0.56$. Relation between the calculated humidity and slopes is weak, $\mathrm{r} 2=0.32$.

\subsection{The results of the study of plant biomass state by NDVI index}

NDVI was calculated (see Fig. 5) using Landsat 8 Oli/Tirs (acquisition date 09 April 2019) and Sentinel-2B (acquisition date 27 April 2019) images for dates that close to the field data of SWC (05 April 2018).
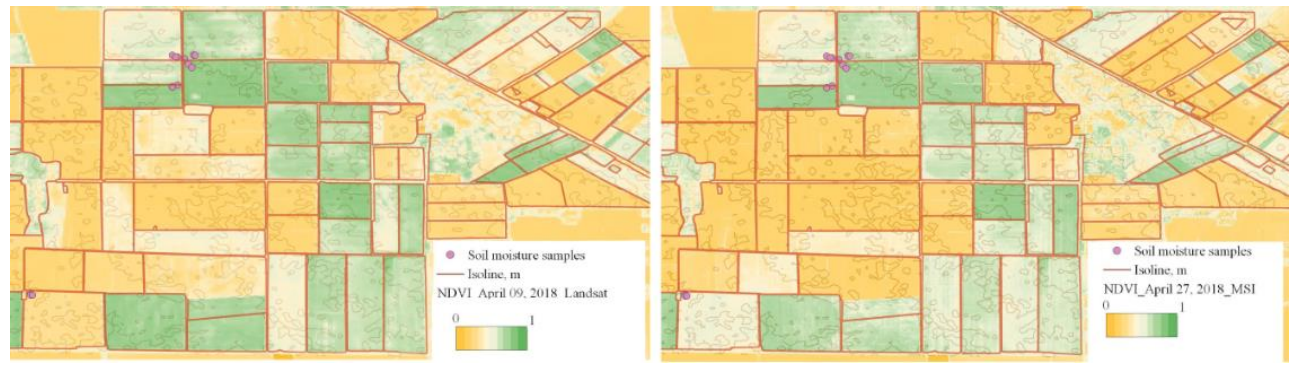

Fig. 5. Remote Sensing data (NDVI) with iso-lines.

Relation between remote sensing data on crops condition and biomass level (NDVI) with soil moisture is strong according to field data, coefficient of determination is $\mathrm{r} 2=0.94$ for Sentinel-2B and r2 $=0.98$ for Landsat 8 Oli-Tirs, respectively. Relation between NDVI 
Sentinel-2B and Landsat 8 Oli-Tirs is strong, $\mathrm{r} 2=0.79$ and $\mathrm{r} 2=0.75$, respectively (see Fig. 6 and Tab.1).

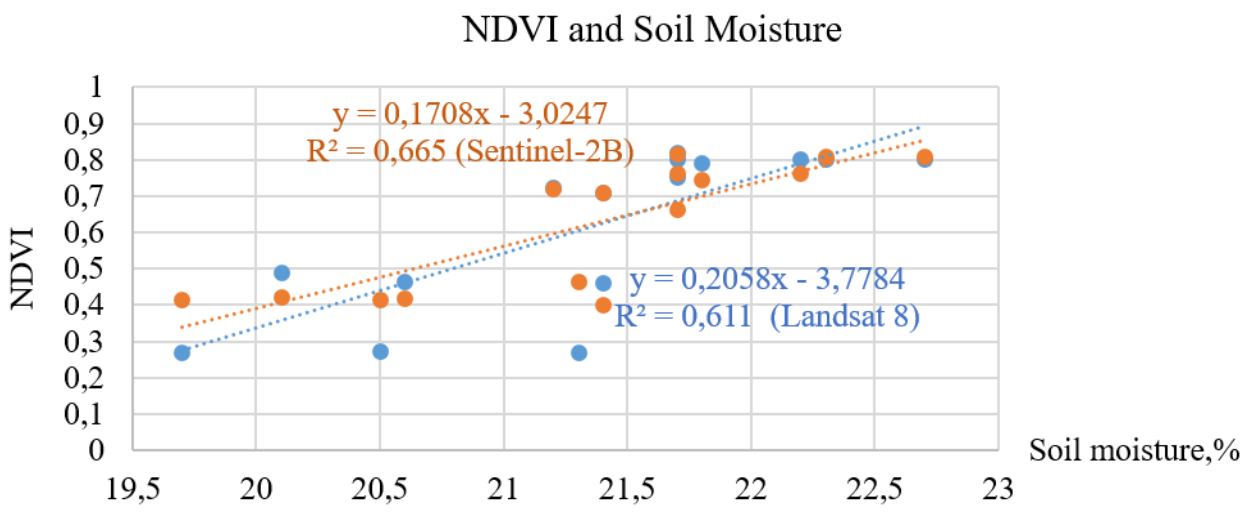

Fig. 6. Relation between NDVI and Soil Moisture.

Table 1. Results (April 2018).

\begin{tabular}{|c|c|c|c|c|c|c|c|}
\hline \multirow{2}{*}{$\begin{array}{c}* \\
\text { Field }\end{array}$} & Crop & $\begin{array}{c}\text { Slope, } \\
\text { degree }\end{array}$ & $\begin{array}{c}\text { Field } \\
\text { data } \\
05.04 .2 \\
018\end{array}$ & $\begin{array}{c}\text { Calculated } \\
\text { QGIS }\end{array}$ & SWAT & $\begin{array}{c}\text { MSI } \\
27.04 .20 \\
18\end{array}$ & $\begin{array}{c}\text { Landsat } \\
09.04 .20 \\
18\end{array}$ \\
\hline 1 & $\begin{array}{c}\text { Winter } \\
\text { wheat }\end{array}$ & 0.464 & 112.60 & 77.27 & 91.80 & 0.70 & 0.72 \\
\hline 2 & $\begin{array}{c}\text { Winter } \\
\text { burley }\end{array}$ & 0.574 & 97.30 & 77.27 & 91.80 & 0.41 & 0.47 \\
\hline 3 & $\begin{array}{c}\text { Winter } \\
\text { wheat }\end{array}$ & 0.220 & 118.70 & 77.27 & 140.70 & 0.78 & 0.80 \\
\hline 4 & $\begin{array}{c}\text { Winter } \\
\text { burley }\end{array}$ & 0.356 & 121.10 & 77.27 & 140.70 & 0.81 & 0.81 \\
\hline 5 & $\begin{array}{c}\text { Spring } \\
\text { barley }\end{array}$ & 0.606 & 89.20 & 66.67 & 91.80 & 0.43 & 0.27 \\
\hline
\end{tabular}

\section{Conclusion}

The investigation of relief effect on moisture distribution in the soil profile showed that height differences affect the amount of soil moisture, and there is a relationship between terrain slopes and soil moisture. Research results confirmed the possibility of estimating the distribution of soil moisture reserves on the territory by direct and indirect methods using DEM. It should be noted that in order to assess the inequality distribution of moisture reserves in one field, it is necessary to divide the field into a grid, select the moisture by key squares, and then analyze by thermostatic-weight method; for indirect methods, the spatial resolution of remote sensing data is the key limiting factor.

The research was carried out as part of theme \#0834-2015-0015 supported by Ministry of Science and Higher Education of the Russian Federation.

\section{References}

1. V.V. Terleev, W. Mirschel, V.L. Badenko, I.Yu. Guseva, Eurasian Soil Science, 50(4), 
445-455 (2017)

2. V.Terleev, E. Petrovskaia, N. Sokolova, A. Dashkina, I. Guseva, V. Badenko, Y. Volkova, O. Skvortsova, O. Nikonova, S. Pavlov, A. Nikonorov, V. Garmanov, W. Mirschel, MATEC Web of Conferences, 53, 01013 (2016)

3. O. Degtyareva, G. Degtyarev, I. Togo, V. Terleev, A. Nikonorov, Y. Volkova, Procedia Engineering, 165, 1619-1628 (2016)

4. A. Nikonorov, V. Terleev, S. Pavlov, I. Togo, Y. Volkova, T. Makarova, V. Garmanov, D. Shishov, W. Mirschel, Procedia Engineering, 165, 1741-1747 (2016)

5. V. Terleev, E. Petrovskaia, A. Nikonorov, V. Badenko, Y. Volkova, S. Pavlov, N. Semenova, K. Moiseev, A. Topaj, W. Mirschel, MATEC Web of Conferences, 73, 03001 (2016)

6. A.W. KrumbachJr, Journal of Geophysical Research, 64 (10), 1587-1590 (1959)

7. Q. Yang, F. Bojie, W. Jun, C. Liding, Journal of Hydrology, 240 (3-4), 243-263 (2001)

8. M.G. Anderson, P.E. Kneale, Journal of Hydrology, 47 (1-2), 115-128 (1980)

9. B.M. Silva, S.H.G. Silva, G.C. Oliveira, P.H.C.R. Peters, W.R. Santos. N. Curi, Agrotecnologia, Lavras, 38(2), 140-148 (2014)

10. L. Brocca, F. Melone, T. Moramarco, V.P. Singh, Journal of Hydrologic Engineering, 14, 153-165 (2009)

11. S.B. Havrylenko, J.M. Bodoque, R. Srinivasan, G.V. Zucarelli, P. Mercuri, CATENA, 137, 298-309 (2016)

12. N.K. Krupsky, N.I. Polupan, Atlas of Soils of the Ukrainian SSR. Soil map of the Republican project institute of land management «UkrZemProekt» («Map of soils of the Ukrainian SSR», 1979) (rus)

13. B. Narasimhan, R. Srinivasan, Agricultural and Forest Meteorology, 133 (1-4), 69-88 (2005)

14. M. Li, Z. Ma, J. Du, Science China Earth Science,s 53 (4), 575-590 (2010)

15. J. Richard, C. Madramootoo, A. Trotman, The development of the SPI and NDVI for 3 study sites in Jamaica, with an investigation into their use in understanding soil water during water stressed conditions in Jamaica, XVIIth World Congress of the International Commission of Agricultural and Biosystems Engineering, Canadian Society for Bioengineering, Quebec, available at http://www.mcgill.ca/files/cariwin/CEF2010_Richards_SPI_NDVI_paper.pdf (data access 15.06.2019) (2010)

16. D. Wang, M. Hejazi, X. Cai, A. Valocchi, Water Resources Research, 47, 09527 (2011)

17. Soil and Water assessment tool theoretical documentation, 2005. p. 102

18. Soil data [Global Modeling and Assimilation Office (GMAO), 2015, MERRA-2 tavgM_2d_lnd_Nx: 2d, Monthly mean, Time-Averaged, Single-Level, Assimilation, Land Surface Diagnostics V5.12.4, Greenbelt, MD, USA, Goddard Earth Sciences Data and Information Services Center, DOI:10.5067/8S35XF81C28F

19. G. Huffman, Precipitation GPM IMERG Final Precipitation L3 1 month 0.1 degree $x$ 0.1 degree V05, Greenbelt, MD, Goddard Earth Sciences Data and Information Services Center, DOI:10.5067/GPM/IMERG/3B-MONTH/05 (2017)

20. D. Mocko, Runoff data, NASA/GSFC/HSL (2012), NLDAS Noah Land Surface Model L4 Monthly 0.125 x 0.125 degree V002, Greenbelt, Maryland, USA, Goddard Earth Sciences Data and Information Services Center, DOI:10.5067/NOXZSD0Z6JGD 
(2012a)

21. D. Mocko, ET data - David Mocko, NASA/GSFC/HSL (2012), NLDAS Noah Land Surface Model L4 Monthly 0.125 x 0.125 degree V002, Greenbelt, Maryland, USA, Goddard Earth Sciences Data and Information Services Center, DOI:10.5067/NOXZSD0Z6JGD (2012)

22. Ie. Dunaieva, Use of means of remote sensing of land in agriculture, St. Petersburg, 6066 (2018)

23. Ie. Dunaeva, Sovremennye problem distantsionnogo zondirovaniya Zemli iz kosmosa, 14(3), 173-181 (2017) (rus)

24. Ie.A. Dunaieva, V.V. Popovych, A.Yu. Melnichuk,W. Mirschel, V.V. Terleev, A.O. Nikonorov, I.A. Togo, Yu.V. Volkova, D.A. Shishov, MATEC Web of Conferences, 265, 04014 (2019)

25. Ie. Dunaieva, Journal of Engineering Research \& Technology, 2(9), 2162-2167 (2013) 